\title{
ANAP

\section{INDICADORES AMBIENTAIS NAS TRÊS MAIORES CIDADES DO AMAPÁ: MACAPÁ, SANTANA E LARANJAL DO JARI}

\author{
Alice Agnes Weiser
}

\author{
Brenda Bezerra Uliana ${ }^{2}$
}

\author{
José Francisco de Carvalho Ferreira ${ }^{3}$
}

\begin{abstract}
RESUMO
Nos tempos que correm relegar as questões ambientais para segundo plano pode ter custos que não estejamos preparados para pagar, em um futuro não muito longe. Com este artigo pretende-se fazer uma leitura da importância do meio ambiente para as três maiores cidades do estado do Amapá (Macapá, Santana e Laranjal do Jari). São utilizados indicadores ambientais, compostos por várias variáveis, que cobrem um vasto rol de assuntos, como esgoto, resíduos sólidos urbanos, biodiversidade, gestão ambiental e qualidade do ar, retirados de fontes oficiais. Os resultados revelam o contrassenso de o Amapá ser um dos estados mais protegidos do Brasil, mas dar pouca atenção ao seu desempenho ambiental. Embora todos as variáveis precisem ser consideradas atentamente, é na água, esgoto e resíduos sólidos que a atenção deverá ser redobrada.
\end{abstract}

PALAVRAS-CHAVE: Indicadores ambientais. Macapá. Santana. Laranjal do Jari.

\section{ENVIRONMENTAL INDICATORS IN THREE LARGEST CITIES OF AMAPÁ: MACAPÁ, SANTANA E LARANJAL DO JARI}

\begin{abstract}
In actual days relegate environmental issues into the background may have costs that we are not prepared to pay, in a future not too far away. With this article we intend to read the importance of the environment issues in the three largest cities in the state of Amapá (Macapa, Santana and Laranjal do Jari). Environmental indicators are used, consisting of several variables, covering a vast array of subjects such as sewage, solid waste, biodiversity, environmental management and air quality, drawn from official sources. The results reveal the nonsense of Amapá be one of the most protected states of Brazil, but pay little attention to their

\footnotetext{
1 Graduanda em Arquitetura e Urbanismo, Universidade Federal do Amapá, bolsista de iniciação científica. E-mail: agnes.weiser@outlook.com.

${ }^{2}$ Graduanda em Arquitetura e Urbanismo, Universidade Federal do Amapá, bolsista de iniciação científica. E-mail: brenda.uliana123@gmail.com.

3 Doutor em Geografia e Planeamento Territorial. Pós-doutorando em Desenvolvimento Regional e bolsista do PNPD/CAPES na Universidade Federal do Amapá. Colaborador do CICS-NOVA da Universidade Nova de Lisboa. E-mail: zfcofer@gmail.com.
} 


\section{ANAP

environmental performance. Although all the variables need to be considered carefully, it is in the water, sewage and solid waste that attention should be redoubled.

KEYWORDS: Environmental Indicators. Macapá. Santana. Laranjal do Jari.

\section{INDICADORES AMBIENTALES EN LAS TRES MÁS GRANDES CIUDADES DEL AMAPÁ: MACAPÁ, SANTANA E LARANJAL DO JARI}

\section{RESUMEN}

En los días que curren, relegar las cuestiones ambientales para según plan puede tener costos que no estamos dispuestos a pagar, en un futuro no muy lejano. Con este artículo se pretende hacer una lectura de la importancia del medio ambiente para las tres ciudades más grandes del estado de Amapá (Macapá, Santana y Laranjal do Jari). Se utilizan indicadores ambientales, que constan de varias variables, cubriendo una amplia gama de temas tales como aguas residuales, residuos sólidos, la biodiversidad, la gestión del medio ambiente y la calidad del aire, procedentes de fuentes oficiales. Los resultados revelan el absurdo de Amapá ser uno de los estados más protegidos de Brasil, pero se presta poca atención a su desempeño ambiental. Aunque todas las variables deben ser considerados cuidadosamente, es en el agua, aguas residuales y desechos sólidos que se debe redoblar la atención.

PALABRAS-CLAVE: Indicadores Ambientales. Macapá. Santana. Laranjal do Jari.

\section{INTRODUÇÃO}

O Estado do Amapá, situado no extremo norte do Brasil, possui $72 \%$ do seu território protegido, entre áreas de proteção ambiental federal, estadual, municipal e privada e Territórios Indígenas. No entanto, há um contrassenso, já que, do ponto de vista ambiental, são muitas as lacunas que apresenta, em vários níveis, sobretudo os que se referem à infraestrutura, fato que é facilmente constatável a partir da observação in loco.

Com este artigo queremos olhar para as três maiores cidades do estado do Amapá (Macapá, Santana e Laranjal do Jari) e analisar como se comportaram os indicadores ambientais entre 2010 e 2014. Para esse efeito, foram selecionados alguns indicadores e observado o seu comportamento neste período de tempo. Como será evidenciado, nem todas as variáveis, por que são compostos os indicadores, têm um valor. 


\section{ANAP $B_{\text {rasil }}$ \\ ISSN 1904-3240 \\ v. 8, n. 13}

O pressuposto inicial é as questões ligadas ao ambiente, mesmo quando são consideradas no planejamento são de difícil aplicação, seja por causa do crescimento populacional elevados nas últimas décadas na área de estudo, seja porque nem sempre é dada a devida importância às questões ambientais, sobretudo por se tratar de algo que nem sempre se vê. E aquilo que não se vê, como sabemos, perde a importância, por exemplo, para políticas mais consentâneas e de longo prazo.

As questões ambientais, embora de entendimento ainda recente, com mais intensidade a partir dos finais da década de 1960, apresentam-se hoje como questões fundamentais, essencialmente no que diz respeito à relação entre o crescimento da população e o consequente aumento do consumo de recursos naturais, à geração de resíduos em quantidade muito mais elevada do que a Terra tem capacidade de absorver e tratar, às questões climáticas (aumento da temperatura média, gases efeito estufa, aumento do nível médio das águas do mar), ao esgotamento dos recursos naturais não renováveis, ao desmatamento, à degradação e destruição da biodiversidade, à poluição da água e solo, etc.

Estamos a vivenciar um momento crítico para a Humanidade, aquele em que a própria espécie humana se pode aniquilar, a partir de uma ameaça silenciosa, que é aquela de ir destruindo o meio ambiente pensando que isso não terá consequências futuras, ou pelo menos em não em um futuro próximo. Os dados que apresentamos neste artigo mostram que é exatamente 0 contrário. No geral, entende-se que nos municípios de estudo os indicadores ambientais pouco ou nada evoluíram positivamente, assinalando que a mudança a operar tem de ser mais contundente, ou, se se quiser, tem de ser ao nível de uma "ruptura urgente", como muito bem afirma Almeida (2007) e Boff (2013).

A partir de indicadores publicados pelo IBGE, pretende-se, com este artigo, mostrar que o desempenho destes indicadores não melhorou significativamente entre 2000 e 2010. Assim, na primeira parte do artigo faz-se 


\section{ANAP

uma apresentação dos três municípios em questão, cobrindo diversos aspectos. Em seguida, apresentam-se os resultados obtidos e os respectivos comentários, que terão como complemento a observação em trabalho de campo, realizado entre 14 de agosto e 02 de outubro de 2015.

\section{CARACTERIZAÇÃO DA ÁREA DE ESTUDO}

\subsection{LOCALIZAÇÃO}

As três cidades estudadas (Macapá, Santana e Laranjal do Jari) localizam-se no estado do Amapá (Figura 1), no extremo norte do Brasil, do qual faz fronteira com a Guiana Francesa ao norte, Suriname a noroeste, com o estado do Pará a oeste e sul, e, a leste, com o Oceano Atlântico. Inicialmente recebeu o título de Território Federal do Amapá em 13 de setembro de 1943, com o objetivo de fazer a proteção da fronteira, se tornando estado a partir de $1^{\circ}$ de janeiro de 1991. Atualmente é constituída por 16 municípios, possui extensão territorial de 142.828,52 km², 669.526 habitantes e densidade demográfica de 4,69\%, segundo o IBGE (2010). É o estado mais preservado do Brasil e o quinto mais urbanizado, atrás, apenas, do Rio de Janeiro, Distrito Federal, São Paulo e Goiânia. 


\section{ANAP $B_{\text {rasil }}$ \\ ISSN 1904-3240 \\ v. 8, n. 13}

\section{REVISTA CIENTIFICA}

Figura 1 - Mapa de Localização

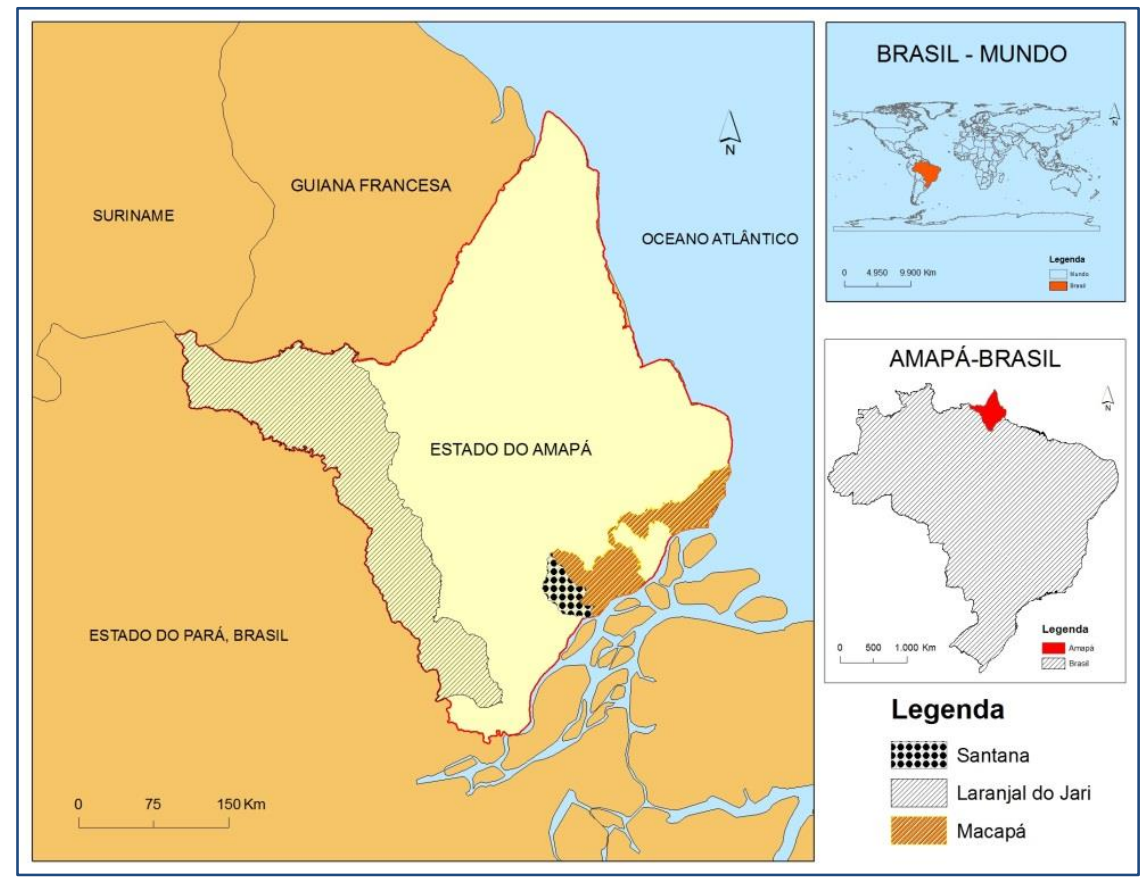

Fonte: Elaboração dos autores. ArcGis 10.1

Macapá, a sudeste do estado do Amapá, é a única capital banhada pelo Rio Amazonas e cortada pela linha do equador. É declarada município pela Lei no 281 dia 6 de setembro de 1856. Possui uma área de $6.502 \mathrm{~km}^{2}$, com taxa de urbanização de 95,73 \%, e apresenta a maior densidade demográfica do estado, com $62,14 \mathrm{hab} / \mathrm{km}^{2}$. Contém apenas $0,05 \%$ de áreas protegidas (SANTOS et al, 2014).

Santana é limitada a nordeste por Macapá, a sudoeste por Mazagão, ao norte por Porto Grande e a leste é banhada pelo rio Amazonas. Santana é a segunda cidade mais populosa do estado, e possui $97,87 \%$ de taxa de urbanização (IBGE, 2010). Em 1981, era considerada um distrito até ser elevada à condição de município em 1987, após ser desmembrada de Macapá. Entre as outras duas cidades estudadas, Santana tem a menor extensão territorial, de 1.569,40 km² (IBGE, 2010) e quase não possui áreas protegidas, apenas $0,07 \%$ (SANTOS et al, 2014). 


\title{
ANAP Brasil \\ ISSN 1904-3240 \\ v. 8, n. 13
}

\section{REVISTA CIENTIFICA}

A localização geográfica de Laranjal do Jari tem grande potencial de integração, pois faz fronteira com o estado do Pará ao sul e oeste, e com Suriname e Guiana Francesa ao norte, além de ser limitado pelos municípios de Oiapoque, Mazagão, Pedra Branca do Amapari e Vitória do Jari. O município de Laranjal do Jari foi criado pela Lei ํㅜ 7.639, de 17 de dezembro de 1987, e, se comparado com os municípios de Macapá e Santana, é o mais distante e possui a maior extensão territorial, com $30.971,8 \mathrm{~km}^{2}$. É considerada uma cidade de pequeno porte e possui taxa de urbanização de $94,89 \%$ (IBGE, 2010).

\subsection{Ocupação territorial}

O estado do Amapá tem sofrido um acelerado processo migratório a partir dos anos de 1980 e um consequente aumento na taxa de urbanização, principalmente nas cidades de Macapá e Santana. Os fatores que contribuíram para este quadro são expostos por Porto (2006, p. 43-44)

\begin{abstract}
O processo de organização do espaço amapaense que em muito afetou a urbanização deste Estado foi decorrente de vários fatores, assim identificados: a defesa da fronteira; a criação do Território Federal; a exploração mineral; a implantação de grandes projetos; a construção de infraestruturas; a construção de company towns; a expansão da fronteira agrícola; a criação de novos municípios; a realização de eleições para o legislativo e executivo municipais e estadual; a estadualização amapaense; a implantação de áreas protegidas; e a implantação da Área de Livre Comércio de Macapá e Santana. Mais recentemente, têm-se a nas obras da pavimentação da BR 156; nas expectativas das obras do PAC do Governo Federal; na retomada da economia mineira e; na implantação de novos Regimes Aduaneiros Espaciais como fortes atrativos para a ocupação das cidades de Macapá e Santana, pois são por elas por onde chegam os migrantes ao Estado.
\end{abstract}

Os investimentos para as cidades de Macapá e Santana influenciaram a configuração atual destas cidades, formando a Região Metropolitana do estado, responsável por concentrar $80 \%$ de sua população (Gráfico 1). Elas 


\section{ANAP

sofrem o processo de conurbação por estarem próximas e estabelecerem ligações econômicas e sociais fortes. São as que mais recebem migrantes de outros estados devido a possuírem a melhor infraestrutura de porto e aeroporto e a concentrarem o maior número de serviços e equipamentos urbanos do estado.

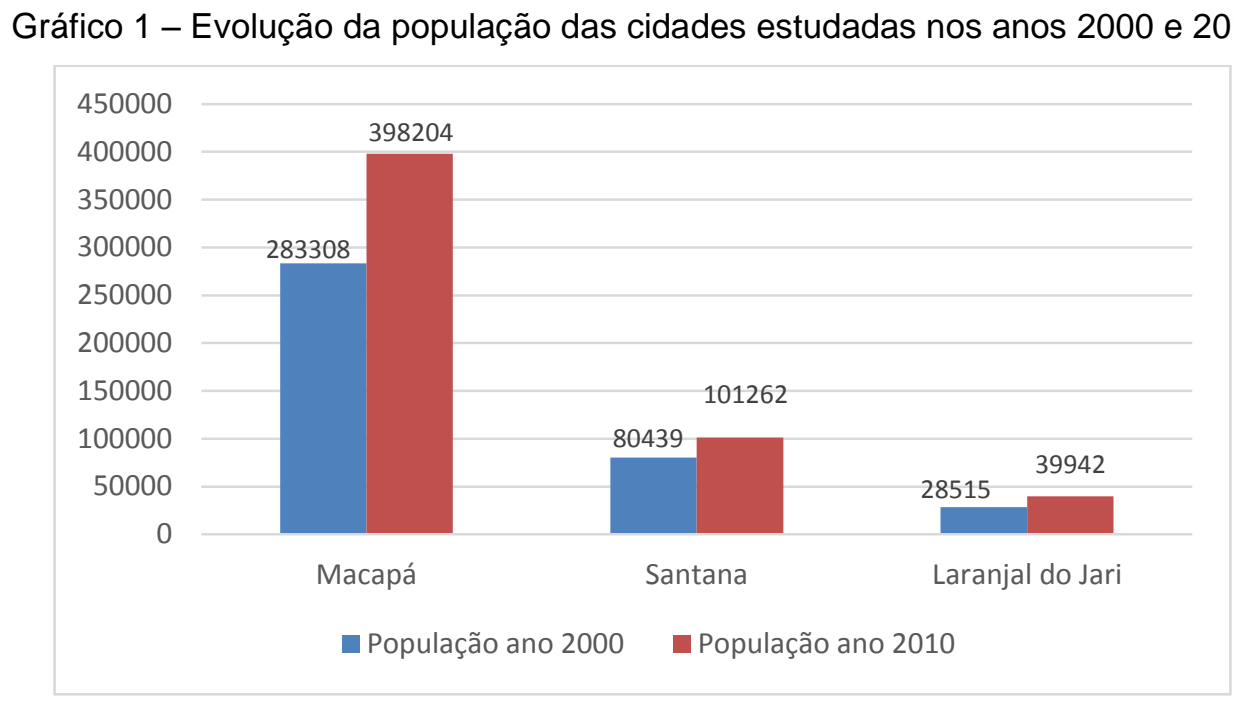

Fonte: IBGE (2000; 2010). Elaborado pelos autores.

Laranjal do Jari é o terceiro município mais populoso do estado que também apresenta crescimento populacional nos últimos quinze anos (Gráfico 1). Os principais indutores deste crescimento também ocorrem em Macapá e Santana, em grande parte ligados às migrações provenientes da implantação de empreendimentos de capital privado. No caso específico de Laranjal, houve como principal influência a instalação da empresa Jari Celulose e do Projeto Jari.

A migração intensa, nas três últimas décadas, para as cidades de Macapá, Santana e Laranjal do Jari tem ocasionado vários desafios às entidades públicas em atendar a demanda da população, gerando alguns problemas, assinalados por Souza (2014): 


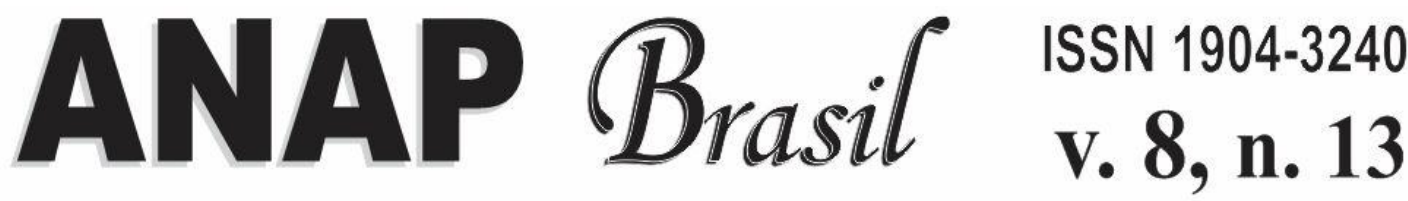

\section{REVISTA C IENTIFICA}

- Pouca oportunidade de emprego e renda;

- Habitação insuficiente e inadequada;

- Transporte público deficiente;

- Saneamento básico precário;

- Incipientes serviços educacionais e de saúde.

Os déficits em habitação fazem com que a população ocupe áreas de baixo custo, entre elas as áreas de ressaca, locais alagados com papel importante em drenar as águas e regular o microclima, consideradas Áreas de Proteção Ambiental (APA). As pessoas que vivem em áreas de ressaca de Macapá e Santana já chega a $20 \%$ do total do estado. O maior núcleo de ocupação de Laranjal do Jari, chamado Beiradão, é considerado a maior favela fluvial do mundo. Formou-se em consequência da instalação da empresa de extrativismo vegetal Jari Celulose no distrito de Monte Dourado-PA, do outro lado do Rio Jari. Esse tipo de ocupação no estado gera vários impactos socioambientais: violência, marginalização, desigualdade social, doenças, poluição do meio ambiente e contaminação de rios (TOSTES, 2011).

Quase todo o território de Laranjal do Jari é constituído por áreas de proteção ambiental (Terras Indígenas e Unidades de Conservação): a Reserva de Desenvolvimento Sustentável do rio Iratapuru, a Estação Ecológica do Jari, a Reserva Extrativista do rio Cajari, a Área Indígena Waiãpi e o Parque Indígena do Tumucumaque TOSTES (2011). Estas áreas apresentam grande potencial para a prática de ecoturismo, quase não explorado na região.

\subsection{Atividades econômicas}

Macapá, por ser a capital, dispõe da maior parte dos serviços e equipamentos urbanos do estado. A cidade tem caráter político-institucional e comercial, concentrando a maior parte das atividades econômicas no setor de serviços, seguindo o setor comercial, destacando-se o atacado e varejo. A orla 


\section{ANAP $B_{\text {rasil }}$ \\ ISSN 1904-3240 \\ v. 8, n. 13}

da cidade (Rio Amazonas) tem papel econômico e cultural importante para o turismo e lazer.

Macapá e Santana fazem integração por meio das rodovias JK e Duca Serra, são espaços de grande importância de articulação entre ambas, que vem se conurbando devido os diferentes usos, a primeira de uso como residencial, institucional e comercial, e a segunda tem o histórico de estar vinculada a projetos econômicos instalados na área, como o Projeto ICOMI, a BRUMASA, ANCEL, PORTO DE SANTANA, DISTRITO INSDUSTRIAL e a ALCMS. A conexão das cidades pelas orlas fluviais não ocorre de forma integrada e são pouco aproveitadas (SOUZA, 2014).

As principais atividades econômicas de Santana estão ligadas à prestação de serviços e ao comércio. Abriga o Parque industrial do estado, que corresponde a $28,6 \%$ do seu território (TOSTES, 2006), e o maior porto do estado, a sua principal porta de entrada e saída de mercadorias e pessoas via fluvial. Além do porto, foi construída uma Estrada de Ferro e uma Usina Hidrelétrica de Coaracy Nunes, com o objetivo de atender a demanda da Indústria de Comércio e Mineração (ICOMI), instalada no início da década de 50 para explorar o minério de manganês no município de Serra do Navio. Após o término da exploração pela ICOMI, em 1997, a estrada passou a ser utilizada para o escoamento de minério e produtos agrícolas.

Laranjal do Jari, assim como as outras duas cidades, desenvolve a maior parte de suas atividades econômicas no setor de serviços, e em segundo lugar no setor agropecuário, em consequência do extrativismo vegetal. Entretanto, a grande parte de sua área protegida tem sido visto como um fator limitante às atividades de agronegócio, mineração e exploração madeireira, tendo como consequência a ocupação e exploração ilegal de terras públicas, a pressão dos atuantes no agronegócio para a transferência do domínio das terras da União para o estado e a maioria da exploração de madeira se dá de forma ilícita.

Revista Científica ANAP Zrasd, v. 8, n. 13, 2015, p. 69-83. 


\section{ANAP $B_{\text {rasil }}$ \\ ISSN 1904-3240 \\ v. 8, n. 13}

\section{REVISTA CIENTIFICA}

\subsection{Planos institucionais}

Em relação aos instrumentos de ordenamento territorial do município de Macapá, desde 1959 têm sido feitos planos técnicos. O primeiro, neste mesmo ano foi o Plano Grumbilf, que também englobava Santana quando ainda era distrito, depois foram feitos dois planos exclusivos para Macapá, um de 1990 e o mais recente, o Plano Diretor Participativo de 2004. Tostes (2006) aponta alguns dos fatores para a ineficácia do PDP de 2004: a não elaboração de planos setoriais; a não revisão do plano em relação ao processo de integração regional e com o município de Santana; a inaplicação do plano no desenvolvimento urbano; a falta de conhecimento e participação dos diversos segmentos da sociedade, entre outros.

Assim como em Macapá e Laranjal do Jari, Santana teve grande aumento na população nas últimas décadas, gerando uma série de problemas socioambientais de desigualdade social e mão-de-obra sem qualificação instaladas em áreas impróprias. Os instrumentos de ordenamento espacial e desenvolvimento urbano criados para o município foram: o Plano Diretor de Desenvolvimento Urbano de Santana de 1993 e o Plano Diretor Participativo de 2006.

Os grandes projetos de capital privado em Laranjal do Jari foram os grandes responsáveis pelo aumento populacional e em consequência sua ocupação desordenada. O processo de urbanização do município de acordo com Tostes (2011) ocorreu distanciado de qualquer concepção planejada, ou melhor, sem planejamento algum, apontando discórdias até então não vividas na região. Foi criado em 2007 o primeiro Plano Diretor Participativo do município para contribuir no ordenamento espacial e no desenvolvimento urbano tão necessário, entretanto ainda não foi efetivado pela gestão pública devido uma série de entraves de questão político-administrativa. 


\section{ANAP Brasil \\ ISSN 1904-3240 \\ v. 8, n. 13}

\section{RESULTADOS E DISCUSSÃO}

Antes de apresentar os resultados, queremos salientar alguns aspectos que nos parecem relevantes para melhor entender os resultados e respectivos comentários. Por um lado, utilizamos variáveis para as quais não existem valores, ou porque não são produzidos ou porque não são coletados. A razão desta utilização é, simplesmente, pelo fato da importância que tem esses indicadores e variáveis para entendermos a pouca importância que se atribui ao ambiente e a necessidade de se olhar com mais atenção para as questões ambientais.

Em outros casos utilizamos as variáveis que existem, mesmo que os resultados os valores possam ser um pouco estranhos, como explicaremos em seguida

Apresentamos, assim, a tabela 1, que mostra os resultados obtidos para o nosso estudo, relativos aos 4 indicadores selecionados.

Tabela 1 - Indicadores e variáveis ambientais em Macapá, Santana e Laranjal do Jari

\begin{tabular}{|c|c|c|c|c|c|c|c|c|c|c|c|}
\hline \multirow{2}{*}{ INDICADOR } & \multirow{2}{*}{ VARIÁVE } & \multirow{2}{*}{ FONTE } & \multicolumn{3}{|c|}{ Macapá } & \multicolumn{3}{|c|}{ Santana } & \multicolumn{3}{|c|}{ Laranjal do Jari } \\
\hline & & & 2000 & 2010 & $\Delta \%$ & 2000 & 2010 & $\Delta \%$ & 2000 & 2010 & $\Delta \%$ \\
\hline \multirow{5}{*}{ Saneamento básico } & Percentual de domic lilios atendidos direta ou indiretamente por coleta de lixo domiciliar \% & IBGE. CENSO & 44,85 & 73,92 & 64,8 & 46,9 & 75,41 & 60,7 & 35,34 & 60,14 & 70,2 \\
\hline & Percentual de domic liios com acesso a rede geral de esgoto ou fossa séptica \% & IBGE CENSO & 18,95 & 23,42 & 23,6 & 10,5 & 14,24 & 36,3 & 0,87 & 8,75 & 905,7 \\
\hline & Esgoto a ceu aberto & IBGE CENSO & 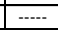 & 55,9 & $\ldots-\cdots$ & 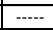 & 52,7 & $-\cdots \cdot$ & $-\cdots \cdot-$ & 70,3 & $-\cdots+$ \\
\hline & Lixo acumulado & IBGE CENSO & $\cdots$ & 15,2 & $+\cdots-\cdot$ & $-\cdots-\cdot$ & 38,0 & $-\cdots \cdot$ & $+\cdots-$ & 20,7 & $\cdots+-$ \\
\hline & Percentual de domiclios atendidos por rede pública de água \% & IBGE CENSO & 53,22 & 48,36 & $-9,1$ & 54,96 & 62,1 & 13,0 & 80,21 & 77,53 & $-3,3$ \\
\hline \multirow{2}{*}{ Gestão Ambiental } & Eetividade da Estrutura de Gestão Ambiental Nro & IBGE Munic. & 0 & 4 & \begin{tabular}{|c|c|}
$\cdots--$ \\
\end{tabular} & 0 & 5 & $-\cdots-$ & 0 & 3 & $-\cdots$ \\
\hline & Eetividade do Conselho Municipal de Meio Ambiente Nro & IBGE Munic. & 0 & 4 & \begin{tabular}{|c|c|}
$\cdots--$ \\
\end{tabular} & 0 & 3 & $-\cdots-$ & 0 & 3 & $+\cdots$ \\
\hline \multirow{3}{*}{\begin{tabular}{|l|}
$\begin{array}{l}\text { Produção, valorização e } \\
\text { destino final dos Residuos } \\
\text { sólidos Urbanos }\end{array}$ \\
\end{tabular}} & Resíduos sólidos com destino a aterro \% & s/inf & 100 & 97,7 & 2,3 & 100 & 100 & 0,0 & 100 & 100 & 0,0 \\
\hline & Taxa de cobertura da coleta seletiva & SNIS & 0 & 0,3 & $-\cdots---$ & 0 & 0 & $-\cdots-$ & 0 & 0 & $\mid--\cdot-$ \\
\hline & \begin{tabular}{|l} 
Residuos recollidos seletivamente por habitante \\
\end{tabular} & s/inf & 0 & 0 & \begin{tabular}{|c|c|}
$\cdots--$ \\
\end{tabular} & 0 & 0 & $-\cdots--$ & 0 & 0 & 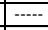 \\
\hline \multirow{6}{*}{\begin{tabular}{|l} 
Biodiversidade/proteção dos \\
ecossistemas
\end{tabular}} & Percentual de área dedicada agricultura Orgânica & sinf & 0 & 0 & \begin{tabular}{|c|c|}
$-\cdots-$ \\
\end{tabular} & 0 & 0 & $-\cdots--$ & 0 & 0 & $-\cdots$ \\
\hline & \begin{tabular}{|l} 
Áreas Protegidas \\
\end{tabular} & IPS & & $0,05^{*}$ & $+\cdots-$ & & $0,07^{*}$ & $-\cdots \cdot$ & $\cdots$ & $94,92^{*}$ & \\
\hline & Área desmatada do município em relação à área total desmatada no estado \% & IGBE & 14,83 & 13,69 & $-7,7$ & 3,59 & 2,54 & $-29,2$ & 7,54 & 6,35 & $-15,8$ \\
\hline & Desperdício de água ( índice de perdas na distribuição de água) & SNIS Mcid & $-\cdots-$ & 77,23 & 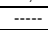 & $-\cdots+-$ & 72,5 & $-\cdots$ & $+\cdots-$ & 85,39 & $-\cdots+$ \\
\hline & \begin{tabular}{|l} 
Áreas degradadas \\
\end{tabular} & IPS & $-\cdots$ & $1,64^{*}$ & $+\cdots$ & 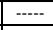 & $0,4^{*}$ & $-\cdots$ & $+\cdots-\cdot$ & $0,05^{*}$ & $-\cdots$ \\
\hline & Consumo de água por habitante (litros/dia) & SNIR & 84,4 & 67,3 & $-20,3$ & 60,3 & 71,5 & 18,6 & 62,6 & 37,4 & $-40,3$ \\
\hline Qualidade do $\mathrm{Ar}$ & Emissōes de monóxido de carbono emitidos por veículo para cada habitante & IBGE & $0,95^{* *}$ & $1,22^{*++\infty}$ & 28,4 & $0,56^{* *}$ & $0,78^{ \pm+*}$ & 39,3 & $0,21^{\star *}$ & $0,37^{*+*}$ & 76,2 \\
\hline
\end{tabular}

Atendendo aos valores da tabela 1, podemos observar que, em alguns casos, houve melhorias nas variáveis. Nas duas primeiras variáveis do indicador "saneamento básico", "percentual de domicílios atendidos direta ou indiretamente por coleta domiciliar" e "percentual de domicílios com a cesso à rede geral de esgoto e fossas sépticas", podemos observar que houve 


\section{ANAP $B_{r a s i}$ \\ ISSN 1904-3240 \\ v. 8, n. 13}

melhorias, sobretudo se se tiver em conta que a população aumentou significativamente neste período de tempo (gráfico 1). A maior variação positiva foi em Laranjal do Jari. No entanto, repare-se que, no caso da segunda variável referida, as percentagens de cobertura são ainda muito baixas nos três municípios. Pelo que se conhece da realidade e por dados do SNIS - Sistema Nacional de Informações sobre Saneamento, em 2010, o esgoto tratado em Macapá tem uma cobertura de $6,06 \%$. Nos três casos, as cidades crescem, mas as infraestruturas não acompanham este crescimento.

As variáveis "esgoto a céu aberto" e "lixo acumulado", embora sem valores para o ano 2000, elas revelam que, em 2010, a situação era bem precária com elevadas percentagens dos territórios urbanos expostos ao esgoto a céu aberto e ao lixo acumulado.

No caso da última variável deste mesmo indicador, "percentual de domicílios atendidos por rede pública de água" as variações não foram muito elevadas, tendo havido inclusive variações negativas no caso de Macapá e de Laranjal do Jari. Recorde-se que nas três cidades a presença de palafitas, ocupando áreas de ressaca, é frequente, mesmo que, em muitos casos, essas casas tenham energia e água canalizada, embora sejam áreas de proteção ambiental e, por isso, lugares onde é proibida a construção de habitações. A título de exemplo, Macapá, segundo dados do IBGE, possuía, em 2010, 60\% de moradias em áreas irregulares de todo o Estado.

Já no caso do indicador "gestão ambiental", nota-se que houve uma significativa melhoria já que, entre 2000 e 2010, surgiram novas estruturas e conselhos ligados ao meio ambiente. As variáveis deste indicador revelam alguma preocupação com o meio ambiente, mas, feitas as relações com as outras variáveis, parece que não é, ainda, suficiente para encarar com a devida seriedade as questões ambientais.

A questão dos resíduos sólidos é, sem dúvida, o "calcanhar de Aquiles" da gestão ambiental. Na verdade, apenas a coleta seletiva melhorou um pouco, mas com valor praticamente insignificante. No estado do Amapá não existe 


\section{ANAP $B_{r a s i l}$ \\ ISSN 1904-3240 \\ v. 8, n. 13}

ainda nenhum aterro Sanitário, contrariando a Política Nacional dos Resíduos Sólidos (Lei 12.305 de 2 de Agosto de 2010). Na verdade, esta é uma questão primordial para a qualidade do meio ambiente e, em consequência, para a qualidade de vida dos amapaenses. Como se pode observar nos valores da tabela, a reciclagem tem valores irrisórios, não existe separação, sendo que praticamente todos os resíduos são destinados a aterro (quando não a lixão), assim como não existe valorização energética dos mesmos. Embora, se comece a notar alguma movimentação por parte das autoridades municipais, a demora encontrar soluções e resolver o problema pode, em muito, comprometer a qualidade no meio ambiente, já no futuro próximo. Repare-se, a título de exemplo, a Área Metropolitana de Macapá, que é composta pelos municípios de Macapá e Santana, onde habita mais de $80 \%$ da população do estado, apenas tem um aterro controlado, que estes dois municípios partilham há alguns anos.

No indicador "biodiversidade/proteção dos ecossistemas", apesar de o estado ser dos mais protegidos do Brasil, com $72 \%$ de sua área sobre proteção, no caso dos três municípios em questão, note-se que ainda existem áreas degradadas, o desperdício de água é mais elevado do país e não existe agricultura orgânica. Há aqui um contrassenso. Estamos perante um estado com alto percentagem de proteção, onde a agricultura orgânica pode ocupar um espaço estratégico e praticamente não existe. Dizemos praticamente, porque se sabe que existe um pouco, mas esta acontece mais por iniciativa privada do que por uma estratégia do estado ou dos municípios. Sabe-se que o estado do Amapá produz muito pouco do que consome, sendo que a grande maioria dos alimentos vem de fora. Ter solos férteis, conservados e alguns sem ser utilizados parece ser, quando a nós, uma enorme displicência.

No caso das variáveis que se referem à água, o nosso intuito era mostrar que, apesar de o estado ser rico em recursos hídricos, a população, em geral, e as entidades públicas, em particular, vivem de costas voltadas para este precioso recurso. Os valores do desperdício são muito elevados. O esgoto 


\section{ANAP $B_{\text {rasil }}$ \\ ISSN 1904-3240 \\ v. 8, n. 13}

a céu aberto, o lixo acumulado, a invasão das ressacas, o aterro controlado e os lixões ainda presentes, revelam que podemos nem estar a perceber que estamos a contaminar este precioso recurso. Algumas caminhadas pelo centro da cidade, pela orla do Rio Amazonas ou mesmo pelas áreas de ressaca nos revelam este triste retrato e criam a ilusão de que a abundância da água, que nunca faltou, é sinónimo de que ela será sempre potável e apta a ser bebida. Isso, como se sabe, não é verdade! É imperioso que se cuide mais do meio ambiente e não se degradem os recursos naturais e os serviços naturais que a natureza nos oferece, a cada instante, gratuitamente.

\section{CONSIDERAÇÕES FINAIS}

O breve exercício feito com este artigo nos mostra que ainda é dada pouca atenção ao meio ambiente. Analisando os indicadores ambientais dos três maiores municípios do Amapá, podemos perceber que o Ambiente, em geral, não tem ainda a importância que deveria ter. Nós, seres humanos, não somos alienígenas! Vivemos em um planeta vivo do qual dependemos para suprir todas as nossas necessidades. O nosso jeito consumista e muitas vezes displicente tem já consequências no Planeta. Não dar a devida importância ao meio ambiente pode ser uma atitude arriscada, se se quiser que a espécie humana sobreviva, prospere e se adapte às mudanças nas condições ambientais no longo prazo (MILLER \& SPOOLMAN, 2012).

A necessária mudança não é somente responsabilidade das autoridades, ela é uma obrigação de cada cidadão, cônscio de suas responsabilidades consigo mesmo, com a natureza e com os outros. Assim, recurso abundante não significa, necessariamente, uma vantagem. Somente quando esse recurso é cuidado e preservado ele constitui uma vantagem. Ter muita água disponível, mas estar imprópria para consumo, em consequência da ação antrópica, não é vantagem alguma. 


\section{ANAP

Em síntese, o que os indicadores mostraram é que a nossa atitude em relação à natureza está a ainda distante dos desafios que hoje se colocam à Humanidade: precisamos consumir menos, cuidar da Terra, produzir menos resíduos, desenvolver atitudes mais ecológicas e colocá-las em prática.

\section{REFERÊNCIAS}

ALMEIDA, Fernando. Os desafios da Sustentabilidade, uma ruptura urgente. Rio de Janeiro, Campus-Elsevier, 2를. 2007.

BOFF, Leonardo. Sustentabilidade: o que é - o que não é? 2.ed., Petrópolis, RJ: Vozes, 2013.

IBGE, Instituto Brasileiro de Geografia e Estatística. Censo Demográfico 2000 e 2010.

MILLER, G. Tyler; SPOOLMAN, Scott E. Ecologia e Sustentabilidade. Tradução da 6 Edição Norte-Americana. São Paulo: Cengage Learning, 2012

PORTO, Jadson L. R. et al. Macapá e Santana (AP): interações espaciais de duas cidades médias na fronteira setentrional amazônica. Trabalho apresentado no XII Encuentro de Geógrafos da América Latina. Montevidéu (Uruguai). 2009.

SANTOS, Daniel et al. Índice de Progresso Social na Amazônia Brasileira. IPS Amazônia 2014. Belém-Pa: Imazon, 2014

SOUZA, Ana Claudia Machado de. Analise do planejamento urbano de um espaço em transformação: As cidades de Macapá e Santana na perspectiva do Desenvolvimento Local. Dissertação (Mestrado em Desenvolvimento Regional), Macapá, Universidade Federal do Amapá, 2014.

TOSTES, José Alberto. Planos Diretores no Estado do Amapá: uma contribuição para o desenvolvimento regional. Macapá: J. A. Tostes, 2006.

TOSTES, José Alberto. Transformações urbanas das pequenas cidades amazônicas (AP) na Faixa de Fronteira Setentrional. Rio de Janeiro: Publit, 2011. 